\title{
Management Control Systems and Integrated Reporting: Which Relationships? The Case of the Azienda Ospedaliero Universitaria Ospedali Riuniti Ancona
}

\author{
Marco Gatti ${ }^{1}$, Maria Serena Chiucchi ${ }^{1} \&$ Marco Montemari ${ }^{1}$ \\ ${ }^{1}$ Department of Management, Università Politecnica delle Marche, Ancona, Italy \\ Correspondence: Marco Gatti, Department of Management, Università Politecnica delle Marche, Piazzale R. \\ Martelli 8, 60121 Ancona (An), Italy. Tel: 39-071-220-7259. E-mail: m.gatti@univpm.it
}

Received: June 12, 2018

Accepted: July 15, 2018

Online Published: August 1, 2018

doi:10.5539/ijbm.v13n9p169

URL: https://doi.org/10.5539/ijbm.v13n9p169

\begin{abstract}
This article explores the contribution that management accountants and management control systems can give to the design and the implementation of an integrated reporting system. In particular, the case of the Azienda Ospedaliero Universitaria Ospedali Riuniti Ancona is analysed in the aim of highlighting the role played by the management accountant in promoting the design and implementation of the integrated report in the specific context under investigation. The empirical evidence adds to the extant literature on this issue by showing the relevant role played by management control systems and by management accountants as well and, in particular, how the latter can significantly influence the whole design and implementation process at an organisational, technical, and motivational level.
\end{abstract}

Keywords: management control systems, integrated reporting, management accountant, healthcare organisations

\section{Introduction}

Among the various control tools adopted, the reporting system is the one which has known the most significant developments over time. In fact, business reporting has progressively been enriched with new forms of reports that have widened the perspective of observation of company performance. Starting from the economic report which is focused on the analysis of variances - normally in financial terms - between objectives and achieved results, new reporting have been proposed. This has led companies to increase the quantity of information provided for external stakeholders and internal users and, at the same time, to favour the transition from a one-dimensional observation of the company performance to a multidimensional view (Eccles \& Krzus, 2010; Yongvanich \& Guthrie, 2006). The intellectual capital report (Buck \& Johanson, 2003; Chiucchi, 2013; Girella \& Zambon, 2013; Guthrie \& Petty, 2000), the environmental report (Clarkson, Overel, \& Chapple, 2011; Grey, Kouhy, \& Lavers, 1995; Niskala \& Pretes, 1995), and the social report (Gray, Owen, \& Maunders, 1988; Guthrie \& Parker, 1989) are just some of the solutions that have been proposed in recent years by academic literature and by practitioners to increase the quantity of information made available to internal and external stakeholders. If, on the one hand, this significant development and diversification of reporting tools has favoured the diffusion of a new perspective of observation of company performance that goes beyond the narrow boundaries of financial performance, on the other hand, it has increased the risk of losing a unitary view of the company performance. The abovementioned reporting tools, in fact, make it possible to produce, as well as use, information focused on specific aspects of performance. Therefore, they do not provide the reader with a holistic view of the company's performance that supports the understanding of its results or of the way they are achieved, i.e., of the ways in which the company has put in place actions and strategies with the aim of generating value over time.

To overcome this problem, the International Integrated Reporting Council (IIRC) has issued a framework for the adoption and the implementation of the "Integrated Report" (from now on, IR). The IR was promoted by the IIRC with the intent to increase the flow of information about the way a company creates value over time to external stakeholders, and to funding institutions, in particular (IIRC, 2013). In this perspective, the IR seeks to overcome the adoption of a dichotomous view of performance by fostering a systemic view of it in which the ability to create value over time is interpreted as the result of the set of actions carried out by a company to transform inputs into outcomes (Abeysekera, 2013; Adams \& Simnett, 2011; De Villiers, Rinaldi, \& Unerman, 2014; Stubbs \& Higgins, 
2014; Van Bommel, 2014). The report integrates different kinds of information within the same document, both financial and non-financial, both quantitative and qualitative, and focuses on different aspects of performance to provide an integrated view of the way a company creates value over time (Cheng, Green, Conradie, Konishi, \& Romi, 2014; Eccles and Krzus, 2010; Girella, 2018; Haller \& Van Staden, 2014; Higgins, Stubbs, \& Love, 2014), hence the name: IR. This ability to integrate different information represents the main element of distinction between the IR and the traditional reporting systems. In fact, the IR goes over the idea that the company performance can be measured resorting solely to financial indicators and it led to a measurement which is multidimensional. Besides this, rather than focusing on economic and financial results, the IR aims to provide a clear explanation of the way a company creates value over time, namely how it combines its inputs to obtain its outputs and outcomes.

The preparation of a complex tool such as the IR requires the participation of various subjects who, in different ways and at different times, are involved in the design and implementation phases. Among these, the management accountant undoubtedly plays a central role, as suggested by the specialised literature on this topic (Busco, Frigo, Riccaboni, \& Quattrone, 2013; Mio, Fasan, \& Pauluzzo, 2016; Oyewo, Obigbemi, \& Uwuigbe, 2015; Wulf, Niemoller, \& Rentzsch, 2014). Although some studies have already discussed the role and the functions attributable to the management accountant and, consequently, to the management control system in the design and the implementation phases of an IR system, the number of empirical studies on the topic remains limited (Dumay, Bernardi, Guthrie, \& Demartini, 2016). This paper aims to contribute to filling this gap in the literature by providing an overview of the variety of functions that management control systems can play with regard to the design and the implementation of an IR system. Moreover, the paper also aims to enhance knowledge on the issue at stake by analysing the IR implementation process carried out in an important national health care institution, the Azienda Ospedaliero Universitaria Ospedali Riuniti Ancona (referred to as AOU). This is done to show the role played by the management accountant and the management control system, highlighting how they contributed to the preparation of the IR in the analysed context.

The paper is organized as it follows. The next section is dedicated to the analysis of the IIRC framework to provide a brief but exhaustive overview of the sections that make up an IR. The third paragraph analyses the extant literature on the role played by management control systems with regard to the preparation of an IR. The fourth paragraph describes the methodological approach followed to carry out the empirical research whereas the fifth introduces the case study and highlights the distinctive features of the particular context under investigation, as well as the development path of the IR. The sixth paragraph illustrates the design of the IR at AOU, focusing on the role played by the management accountant and the management control system. Finally, some concluding remarks are presented.

\section{The IIRC Framework}

In December 2013, the IIRC issued the International Integrated Reporting Framework, which is the set of principles that define the content of an IR and support its preparation. Particularly relevant is the definition that the framework provides of the IR and its purposes: "The primary purpose of an integrated report is to explain to providers of financial capital how an organization creates value over time" (IIRC, 2013, p. 4). Therefore, it is clear that the IR is primarily oriented to external stakeholders, in particular those who provide capital (Serafeim, 2015), but also to suppliers of goods and services, to business partners, etc. Through the IR, these stakeholders have the opportunity to understand how a company generates value and how it aims to continue to do so in the future (Barth, Cahan, Chen, \& Venter, 2017; Frías-Aceituno, Rodríguez-Ariza, \& García-Sánchez, 2013). In fact, showing how value is created by an organisation, an IR contributes to build a good image among capital providers who, in turn, could be more willing to support its activity and, consequently, to improve its ability to create value in future.

Leaving aside the principles underlying the preparation of an IR and focusing attention on its content, the framework specifies that an effective IR should consist of eight fundamental sections (IIRC, 2013):

- presentation of the organization and of the external environment;

- analysis of the governance structure through which the company creates value;

- definition of the business model adopted;

- analysis of risks and opportunities related to the company's ability to create value in future;

- definition of the resource allocation strategies, i.e. the objectives that the company aims to pursue in the future;

- development of the performance measures through which the company shows if and how it has achieved its objectives; 
- analysis of the main future development perspectives of the company and the related effects on the company strategy;

- criteria underlying the choice of information to be included in the IR.

The underlying assumption of an IR is that the company's ability to create value over time is strictly dependent on the way in which it combines, in its business model, those factors that the framework calls the 'capitals' available, thus increasing their value over time (Adams, 2017; Beck, Dumay, \& Frost, 2017; Loprevite, Bruno, \& Ricca, 2018). By analysing the capitals, one of the main features of the IR emerges, that is, the fact that it integrates information and indicators, often presented in various separate company reports, into a single document, thereby providing a systemic and holistic view of the company's performance and of its ability to create value in the future (Abeysekera, 2013; Thomson, 2015; Van Bommel, 2014). The capitals are identified by the framework as follows (IIRC, 2013):

- financial capital, related to the financial resources that the organization uses to produce goods or to provide services:

- manufactured capital, inherent to the tangible assets used by the company in the production process;

- intellectual capital, interpreted as the set of intangible resources used to support management;

- human capital, referring to the set of skills and abilities of the human resources employed in carrying out the company's activity;

- social and relationship capital, represented by the relationships established with the external and the internal stakeholders of the organization;

- natural capital, identified as all the resources, renewable and non-renewable, that provide assets for the past and future success of the organization.

The value produced by the company, therefore, will depend on its ability to use the capitals in question within its business model, and increase their value over time (Abeysekera, 2013; Cheng, Green, Conradie, Konishi, \& Romi, 2014; Lodhia, 2015; Perego, Kennedy, \& Whiteman, 2016). For this reason, the column of inputs, broken down into the capitals described above, stands opposite to the outcomes column, also organized according to the six capitals; they represent the fields in which the company is called to identify indicators, both financial and non-financial, that can give evidence of growth in the capitals themselves over time. The corporate business model, which, according to the IIRC (2013, p. 25), is "the system of transforming inputs, through its business activities, into outputs and outcomes that aims to fulfil the organization's strategic purposes and create value over the short, medium and long term", is located within the inputs and the outputs, as it encompasses the set of business activities and outputs through which changes in the value of the capitals contemplated in the framework are made possible (IIRC, 2013).

The need to combine within the same report such different measures and information, with reference both to their nature and to the object of observation, allows, on the one hand, to highlight the ability of the IR to holistically represent the way in which the company creates value and, on the other hand, to stimulate reflections on the role that the management accountant and the management control system must necessarily play with regard to the preparation of a document of fundamental importance for corporate communication (Kerr, Rouse, \& De Villiers, 2015). It is to this aspect that specialised literature has begun to pay attention, analysing the role that the management accountant and the related management control system could, and should, play with regard to the design and the implementation of an IR.

\section{Management Control Systems and IR: A Review of Literature}

Starting from the publication of the IIRC framework, analysis of the IR, as a tool, and its diverse aspects has come to the forefront, not only from the academic literature, but also from other arenas. Attention has been paid to both the design and the implementation of the IR in different contexts ranging from healthcare to non-profit organisations (Adams \& Simnett, 2011), as well as to the diffusion of this tool in specific countries (Feng, Cummings, \& Tweedie, 2017; Gunarathne \& Senaratne, 2017; Guthrie, Manes Rossi, \& Orelli, 2017; Manes Rossi, Nicolò, \& Orelli, 2017; Paolucci \& Cerioni, 2017). Moreover, research has also carried out a comparison between the IR and the sustainability report (Jensen \& Berg, 2012), with the aim of highlighting how integrated reporting can effectively ensure the implementation of sustainability strategies (Adams, 2014; Brown \& Dillard, 2014; Flower, 2015; Thomson, 2015). The IR has also been studied and analysed as a tool able to foster changes within organizations (Guthrie, Manes Rossi, \& Orelli, 2017; Stubbs \& Higgins, 2014) with regard to both the way information is disseminated outside and to the internal diffusion of dominant cultural values. The significant 
number of contributions on this topic has already led several authors to systematise the knowledge produced as well as to suggest new areas of research that could be the object of future studies (Burke \& Clark, 2016; De Villiers et al., 2014; De Villiers, Venter, \& Hsiao, 2017; Dumay et al., 2016; Velte \& Stawinoga, 2016).

Despite the growing number of contributions on the IR, the analysis of the role played by management control systems with regard to its preparation and implementation remains an under-explored theme (De Villiers et al., 2017; Dumay et al., 2016; Perego et al., 2016). Contributions that do broach this topic have attributed to management control systems a central role in the design and implementation of an IR (Busco et al., 2013; Chartered Institute of Management Accountants, 2017; Mio et al., 2016; Oyewo, et al., 2015; Wulf et al., 2014; Trébucq \& Magnaghi, 2017). This role manifests itself in two different perspectives: at a technical and an organizational level. From a technical point of view, what is requested of management accountants and management control systems with regard to the preparation of an IR seems to primarily concern the production of the necessary information and the calculation of the indicators relating to the six capitals (Chiucchi, Montemari, \& Gatti, 2018; Jinga \& Dumitru, 2014). However, the design and the preparation of an IR appears to be an activity that falls somewhere in between the two and represents, in reality, a critical and complex activity (Busco, Frigo, Quattrone, \& Riccaboni, 2014). In fact, the need to carry out measurements with reference to the six capitals leads management control systems to identify new and multidimensional indicators that move the task of management control systems far beyond the mere production of financial information (Institute of Management Accountants, 2016). The implementation of an IR requires defining a set of indicators that are often starkly different from those that the most common and widespread management control systems are asked to produce (Steyn, 2014; Velte \& Stawinoga, 2016). This is because they relate to areas of the company that are not always subject to measurement and may be quite different from those contemplated in the most widespread corporate reports (Guthrie et al., 2017; McNally, Cerbone, \& Maroun, 2017). This criticism is even more relevant for healthcare and public organisations since, according to Adams and Simnett (2011), costs to provide additional information can represent a relevant barrier to the adoption of an IR in these organisations. While it is true that this role attributable to management control systems could be facilitated by the existence of strategic control tools (Giovannoni \& Maraghini, 2013; Mio et al., 2016), which denotes a greater inclination to operate not necessarily, or not exclusively, using operational and financial measures, it is also true that the increasing quantity of differentiated information that the preparation of an IR makes it necessary to provide can be a source of criticism. This is even more evident in those realities characterized by the use of management control systems that are not particularly flexible, in which the production of new information could represent a real obstacle to the preparation of an IR (McNally et al., 2017). According to Guthrie et al. (2017), in public sector organisations and, consequently, in healthcare organisations, management control systems often need to change logics to support the preparation of an IR. Therefore, when this change does not occur, the design, the implementation and the use of an IR can be problematic.

Regarding indicators and information, it should also be argued that specialised literature attributes to management control systems an important function in terms of guidance and support in the selection of useful indicators to allow an adequate monitoring of the six capitals (Busco et al., 2014; Mio et al., 2016). In this perspective, management control systems play the role of 'guarantor' of the principle of materiality according to which the preparation of an IR should be guided by the need to provide only the information and indicators that are truly significant, or able to explain the company's ability to generate value in the short, medium, and long term. The identification and selection of indicators can only be attributed to the management accountant, not only because of his familiarity with aspects related to measurement but also, and in particular, for his in-depth knowledge of the company information systems from which information and indicators are collected (Busco et al., 2014; Oyewo et al., 2015). With regard to this, literature has underlined how such knowledge could be pivotal for the preparation of an IR also because of the need to integrate data that is produced from different sources (Owen, 2013; Velte \& Stawinoga, 2016). In this perspective, the knowledge that the management accountant has about the company information systems can play a central role with regard to the identification of proxies already available which, although they do not represent the best solutions for measuring specific aspects of the company performance, can ensure an effective approximation of indicators which would otherwise have to be calculated by incurring additional costs in terms of both time and financial resources.

Another important role attributed by specialised literature to management control systems, with regard to the preparation of the IR, concerns organisational issues (Busco et al., 2014; Steyn, 2014). Scholars have highlighted that the management accountant plays, or should play, a fundamental role in the preparation of an IR because it is his role to encourage the development of a high degree of communication within the organisation and with external stakeholders. Basically, the management accountant is responsible for establishing effective internal and 
external communication flows aimed at encouraging the production, selection and, finally, the use of information presented in the IR (Barth et al., 2017; Chartered Institute of Management Accountants, 2017). In this perspective, the dialogue with internal users is instrumental to the generation of a collaborative and participatory environment which represents a prerequisite for the preparation of an IR that requires the production of information from different business areas and from different sources, as previously mentioned (Institute of Management Accountants, 2016; Trébucq \& Magnaghi, 2017). At the same time, the activation and maintenance of effective communication channels with external parties is pivotal to facilitating the identification of those aspects of corporate performance which are of particular interest to the final users of the document. In fact, they represent those aspects that should be worthy of very careful consideration in the IR. From an organisational standpoint, specialised literature recognises the management accountant's role in supporting the diffusion of a corporate culture that is more oriented to the strategic aspects of management rather than to the operational ones (Busco et al., 2013; Dumay \& Dai, 2017; Mio et al., 2016; Steyn, 2014). This means that the management accountant should be able to spread strategy as well as the corporate mission and vision among workers and middle-managers since this is prodromal to encouraging the highest level of participation in the preparation of an IR as well as its diffusion and usage within the organisation. Therefore, the management accountant is in charge of generating greater awareness of the company's strategy within the organisation, especially among all those who, directly or indirectly, take part in the preparation of the IR (Wulf et al., 2014). It should be underlined that this role is particularly relevant in public organisations and in healthcare organisations given that the lack of a market pressure to account about performance can slow down the adoption and the implementation of IR. Therefore, the presence of a management accountant able to generate awareness about strategic issues is fundamental to limit these problems (Veltri \& Silvestri, 2015).

What has been briefly outlined above shows the multiplicity of roles attributed to the management accountant and to management control systems with regard to the preparation of the IR. However, there still seems to be a scarcity of empirical analysis of the issue, in the literature. In the sections that follow, this article aims to contribute to bridging this gap by presenting the case of the AOU, an Italian hospital group that is a leader at both the regional and national levels, and that has recently prepared its first IR inspired by the IIRC guidelines. In particular, after outlining the reasons underlying the choice to implement an IR and the steps that led to its preparation, attention will shift to the role played by the management accountant and the management control system in the design phases of the IR and to the criticisms and difficulties that were faced during its preparation.

\section{Research Method}

To highlight the contribution given by the management accountant and management control systems in the design and the implementation of an IR, an interventionist research project was carried out (Dumay, 2010; Jönsson \& Lukka, 2005; Suomala, Lyly-Yrjänäinen, Laine, \& Mitchell, 2017). Interventionist research implies a direct intervention of researchers in the field in an attempt to give a contribution from both a theoretical and a practical standpoint. In particular, the research was conducted using a "strong" interventionist approach (Dumay, 2010; Kasanen, Lukka, \& Siitonen, 1993; Lukka, 2000, 2005). In fact, researchers began their investigation in the field in February 2017, when the analysed organisation decided to start preparing the report related to the year 2016. The AOU was already in touch with two of the researchers who had already contributed to the preparation of previous reports. This made it easier for the researchers to be considered and perceived as 'insiders' (Jönsson \& Lukka, 2005), given that they were well known by those who took part to the design and the implementation of the IR. As previously stated, the intervention was strong since researchers led the whole design process and they coordinated, and consequently were responsible for, every single stage.

The team was called to support the organisation in the design and the implementation of the IR. It should be underlined that, as previously stated, the preparation of a report did not represent a new challenge for the AOU. Rather, what was new was the peculiar reporting scheme that the organisation wanted to adopt: that suggested by the IIRC. Thus, the team was asked to drive the design stage, favouring the effective implementation of a new kind of report, the IR. In so doing, it had the opportunity to explore and to analyse in vivo the contribution given by the management accountant and management control systems; in addition it helped in the actual preparation of the IR.

To collect data, researchers mainly used participant observation. In fact, the team took part in all the meetings with the management accountant and the other people involved in the project. This allowed them to observe the role played by the management accountant in practice but also, and in particular, to interpret it in light of the specific and peculiar context in which he worked. In addition, documental analysis provided other relevant information. In particular, previous reports were deeply analysed to provide a full understanding of the path leading up to the IR and of the changes that occurred in the reporting system before the decision was made to 
adopt the IR. Moreover, internal documents, like those concerning the organisation's mission and vision as well as other programmatic documents were analysed to collect information on those aspects of the organisation which were deemed worthy of inclusion in the IR as they were expected to contribute to value generation in the long term. Moreover, documents related to the existing information system were analysed in order to have a clear idea of what already existed and, consequently, of what the management accountant and the management control systems were expected to do to support the preparation of the IR. Finally, informal talks with the management accountant as well as with the medical staff involved in the project and the top managers were fundamental to gaining information on the peculiar context under analysis and on perceptions about the IR.

Information collected through participant observation, document analysis, and informal talks was the object of a triangulation process among researchers involved in the research project. This was significant for two main reasons. First and foremost, it allowed the team to also benefit from a different viewpoint in the interpretation phase, that of the third researcher who did not personally participate to the project. Second, it made it possible to contrast and compare personal feelings with information collected through documental analysis in an attempt to strengthen the interpretation process and, in particular, to make it more reliable.

\section{The Design of the IR at the AOU}

The AOU was established by Regional Law n. 13 of 20/06/2003 through the incorporation of three hospitals and the integration with the Università Politecnica delle Marche, hence the name University Hospital. Today the AOU comprises three hospitals which include 3,532 employees of the National Health Service and 124 University employees. The mission of the AOU is focused on four key elements:

- to integrate and to develop scientific and applied research;

- to be a local, national, and supranational reference hospital;

- to increase communication, sharing, and transparency;

- to promote efficiency and sustainability.

The preparation of the IR represents the last step of a process of accountability undertaken by the AOU as early as 2013, when the organization's first social report was honoured by the Italian Federation of Public Relations with the award for the best social report for Italian public administrations. Since 2013, the accountability path has remained steady. In fact, the social report continually improved up to 2015, when the configuration of the institution's first IR became completely aligned with the 2016 edition of the IIRC guidelines. The AOU's path was constantly followed by a group of researchers from the Department of Management of the Università Politecnica delle Marche (referred to as 'the team') who assisted the management accountant during the entire process of building the social report, first, and then the IR.

There were essentially three phases in the AOU's implementation of the IR. In the first, the team's objective was to generate consensus for the new tool. The year 2017, in fact, marks the transition from the social report to the first IR prepared by the organisation. To this end, the General Manager created a project team of key participants consisting of the (research) team, the General Manager himself, the Head of the Accounting and Finance department, the Head of the Health department, and the management accountant. This key group was involved in a series of training meetings whose objective was that all members gain a full understanding of the main purposes underlying the IR, know the role that each of them was expected to play in its preparation, and be aware of who the stakeholders were that represented the main readers of the final documents. The training sessions constituted the first step. It was immediately followed by the second step which was mainly focused on identifying the indicators that would be used to measure the six capitals of the IR and on developing the related business model.

In this second phase, the research team developed an initial set of indicators and worked with the people involved in the project to reflect on and develop the corporate business model. This modus operandi was possible and progressed seamlessly, given that, as stated before, the AOU came from the prior successful reporting experience of the social report. Therefore, many of the indicators that had been produced for the preparation of the social report could be usefully adopted in the IR, drawn up according to the IIRC model, as they had already been calculated by the existing information system. This undoubtedly facilitated the process of identifying indicators. However, the decision to adopt the IR model proposed by the IIRC also made it necessary to identify new indicators to measure aspects of company performance not contemplated in previous corporate reporting experiences (Guthrie et al., 2017; McNally et al., 2017). The preliminary set of indicators, together with the first version of the business model, both suggested by the team, were shared among the project participants. It should be noted that, during the phase 2 meetings, some critical issues emerged concerning both 
the proposed indicators and the business model. With regard to the former, some of the proposed indicators could not be calculated using the existing information system, unless the AOU was willing to incur costs and to invest time in a way which was substantially incompatible with the timing of the IR (Steyn, 2014; Velte \& Stawinoga, 2016). Therefore, there clearly emerged the need to revise the set of indicators, eliminating those for which there was no possibility of calculation and resorting to proxies for those that, although they were not calculable by the existing information system, were considered essential to ensuring the best communication with reference to the connected capital (Oliver, Vesty, \& Brooks, 2016). In parallel, the complexity of the AOU organizational model stimulated deep reflections on the business model that had changed over time and in connection with the introduction of new dimensions not originally contemplated. Their consideration within the AOU business model stemmed from to the need to better reflect on the process through which the AOU generates value for its end users. After having reached agreement on the indicators and the key dimensions of the business model, the management accountant was involved in determining, for each indicator, the data source, the way it was expected to be calculated, and the person in charge of its calculation and collection. This was followed by the dissemination of the abovementioned information among the various organizational units involved and the subsequent collection of the information in a database.

The completion of the information gathering phase effectively marked the beginning of the third and final step in the IR implementation process, consisting in the preparation of the IR. In this phase, a key role was played not only by the management accountant, but also by the team (Stubbs \& Higgins, 2014; Guthrie et al., 2017), which guided the identification of what could have been a simplified, but effective, index of the new IR for the AOU. The definition of the index and its subsequent sharing with the internal team represented a central moment as it was instrumental in facilitating the reading of the document by stakeholders. In fact, the IR needed to be structured in such a way as to be easily understood and read by the end users. Moreover, there was also the need to supplement the indicators with detailed information that would provide explanations of medical terms not always immediately comprehensible to those who would be the final readers of the document. The design phase ended with a shared agreement on the definitive structure of the IR. The preparation phase immediately began. Once completed, according to the IIRC guidelines, the first IR was presented to all of the hospital group's stakeholders.

\section{The Role of the Management Control System to Support the Design of the IR at the AOU}

To understand the role played by the management accountant and by the management control system with reference to the design and the implementation of the IR at the AOU, the features of the existing management control system and of the context in which it operated cannot be overlooked (Dumay \& Dai, 2017, Guthrie et al., 2017). The management control system of the AOU is a system based on traditional management accounting tools. In particular, the company adopts a budget whose preparation follows a time-tested process, a management accounting system based on cost centres and processes and, finally, a reporting system focused on the objectives identified in a long-standing plan primarily aimed to highlight the level of achievement of targets on a monthly basis. Even in the absence of strategic control tools, the degree of structuring of the management control system of the AOU can be said to be high. In fact, over the years, the system has been updated and improved with the aim of making it able to support the increasingly complex decision-making processes of an expanding health care organisation such as the AOU. With regard to the context in which the management control system operated, it should be underscored that it is a very peculiar context, as literature has often pointed out (Manes Rossi, 2018). The health sector, in fact, is characterized by the coexistence of figures with profoundly different skills. In particular, the administrative staff must work with the medical staff. Despite their considerably different skills, both are called to collaborate to ensure the functioning of organisations in which the quality of service is a condition, and at the same time a consequence, of careful management activity. This can generate critical issues that concern the difficulty of finding information useful for carrying out management control activities which are often produced, or directly managed, by the medical staff. Moreover, problems also arise with regard to the role assigned to the management control system and, consequently, to the management accountant within the organizational structure. The different skills, combined with the often limited mutual knowledge of the respective functions, make it difficult to identify the controlling area as a pivotal one in organisations operating in the health sector. Rather than being a privileged interlocutor with whom to interface in an effort to obtain useful information to support corporate decision-making processes, the management accountant is often seen in a different light, namely as the subject who sets targets and controls over their achievement although objectives are often perceived as not really able to represent the activity carried out in the medical area. This criticality was also found, in part, at the AOU where both the management control system and the management accountant are the object of resistant behaviours. In the analysed context, this was substantially attributable to the perception that 
the management control system required increased time and resources added onto what is, instead, the primary institutional activity of the organisation, namely the medical and outpatient activity. However, it should be emphasized that, at the AOU, the controlling area had always been held in good esteem and enjoyed unconditional confidence of the General Managers over the years, regardless of whether their personal backgrounds were medical or administrative. This mitigated, at least in part, the practical problems related to the introduction of a purely administrative activity in a prevalently medical context.

It is starting from this scenario that it is possible to fully understand the role played by the management accountant and the management control system with reference to the design and the implementation of the IR at the AOU. Contrary to what is found in the literature and often in practice, in the case under analysis the management accountant did not play a central role with reference to the decision to adopt the IR. While she firmly believed in the potential of the tool, the idea of expanding and refining the information for those outside the AOU through the IR came from the General Manager. This ensured, from the earliest stages, a strong sponsorship for the project by top management, and undoubtedly facilitated the subsequent steps of the design and implementation of the IR. In these steps the management accountant and the management control system played a fundamental role from an organizational, technical, and motivational point of view.

With regard to organizational issues, the intervention of the management accountant manifested itself during both the preparation phase for the IR design process and the actual design phase of the tool. In fact, in the phases immediately preceding the start of the design process, the management accountant was asked to identify people who would be directly involved in the project, establishing, for each of them, the modes of involvement as well as the level of intervention required. Although the composition of the project team was subject to approval by the General Management, the fact that the management accountant was asked to define its composition and the related roles of the members proves the level of trust that the top managers placed in her. Also from an organisational standpoint, the importance of the management accountant's role emerged during the design stage of the IR, in particular. It is with regard to this phase, in fact, that the management accountant played a central function in terms of guiding and coordinating the whole process. Particularly relevant and peculiar is the fact that the management accountant was not formally appointed by top management to play this role. Rather, the internal dynamics, professional as well as human, resulted in her taking on such a critical function. In other words, her personal, professional and relational skills hindered the rise of those barriers which, as previously stated normally emerge in the health sector when a management accounting tool needs to be implemented.

Equally important was the role played by the management accountant and the management control system with regard to the technical aspects related to the design and implementation of the IR. In fact, the empirical evidence seems to support what has been discussed in the existing literature on this topic. In particular, the role of the management accountant and of the management control system has clearly emerged as pivotal in terms of providing support in the calculation of the indicators that had to be produced to make the IR preparation possible. This support was two-pronged. On the one hand, to the management accountant helped with the task of determining the best indicators to guarantee an effective measurement of the capitals considered in the IR. With regard to this activity, what might appear to be routine for the management accountant is, instead, a pivotal activity when the design process is entrusted to a team of people who are not part of the company to which the IR refers. In this case, in fact, the presence of an internal figure ensures immediate feedback regarding the selection of the indicators and their reliability. In the case of AOU, the management accountant played a central role in evaluating the different indicators proposed by the team because she was able to inform them concerning those that could be calculated, at least in theory, and those for which no measurement was possible. The contribution given by the management accountant, however, cannot and should not be observed and analysed only in terms of her ability to ascertain the calculability of the indicators proposed by the team. In fact, the management accountant's deep knowledge of the company information system allowed her to play a much more active role that manifested itself in terms of support in the identification of alternative indicators, or of reliable proxies, when the solutions proposed by the team were not available or calculable (Owen, 2013; Wulf et al., 2014).

On the other hand, the management accountant also provided support from a technical perspective which primarily concerned the revision of the IR scheme proposed by the IIRC and adapting it so the final document would more effectively respond to the information needs of the AOU's stakeholders. In the design stage of the tool, in fact, the management accountant had repeatedly drawn the project team's attention to the need for changes to the scheme suggested by the IIRC, the aim being to facilitate the reading and understanding of the document by all the company stakeholders, especially those less well-versed on health issues but, in any case, fundamental for the AOU, such as the hospital patients. From a technical point of view, therefore, the 
management accountant was fundamental since she ensured the best usability of the document. Thanks to both her deep knowledge of the context and her thorough understanding of the IR, she was able to intervene and interface with the team at a peer level, acquiring over time the credibility that allowed her to propose, and to make acceptable, important changes to the IR structure proposed by the IIRC. This active participation is, in part, also linked to some of the management accountant's personal characteristics or to her aspirations for professional and personal growth. In this perspective, participating actively in the preparation of the IR, becoming a real 'architect' and going beyond the mere definition of indicators, was understood and interpreted by the management accountant as an opportunity for learning which, in the last instance, produced important benefits for the whole team (Burke \& Clark, 2016; Chartered Institute of Management Accountants, 2017).

The specific context under investigation makes it possible to highlight how the management accountant played a pivotal role also from the motivational perspective. In fact, during the whole IR design and implementation process, the management accountant demonstrated a constantly positive and proactive attitude towards the project. This had a double effect: on the one hand, it speeded up the whole process, encouraging discussion as well as the sharing of information. On the other hand, it created a favourable climate for the implementation of IR; that is to say, it stimulated those who took part in the project to take a positive and proactive attitude from the beginning of the design phase of the IR. Moreover, in addition to the previously analysed roles of guide and architect, the management accountant also took on that of 'animator' of the design process. The IR training path undertaken by the management accountant further encouraged and strengthened this role. In fact, despite the previous experiences of social reporting, the introduction of the IR represented a very important moment of "disruption" for the AOU. It was a time of transition to a new model of reporting that, as such, had to be understood and fully appreciated. The intense training on the technical, processual, and implementation aspects of the IR that the management accountant conducted allowed her to achieve credibility and gain the esteem and appreciation of the people involved in the project. In this sense, being guided by an internal person who was perceived to be competent on issues related to integrated reporting further encouraged the establishment of a collaborative approach to the design and the implementation of the IR.

However, it is with regard to the abovementioned barriers related to the peculiar context that it is possible to further appreciate the contribution given by the management accountant in terms of motivation. On several occasions, during the design and preparation of the IR, the management accountant had to interface with the medical staff persons, who were often either the suppliers of data instrumental to the calculation of the indicators or were the people appointed to verify the correctness of some critical information regarding hospital services provided to users. The existence of these barriers could have represented a significant obstacle. However, even in this case, the concrete support of the management accountant was of fundamental importance. In fact, through her excellent interpersonal skills and an equally strong sponsorship given by the top management, she was able to communicate to the medical staff the importance not only of the tool that was going to be implemented, but also and above all, of their participation in its design and implementation. In doing so, she managed to get the medical staff involved in a design process which was neither simple nor obvious in its outcome, especially in a complex health sector reality like the AOU. In light of all the above, the management accountant was instrumental in foreseeing and preventing barriers that could have hindered the adoption of the IR.

\section{Conclusions}

The IR is rapidly becoming, by now, a reality in most of the companies that have decided to adopt the practice of reporting that is mainly oriented to the outside. The design and the implementation of an IR, however, represent phases of a more complex process in which the management accountant and, more generally, the management control system can and should play a pivotal role (Busco et al., 2013; Chartered Institute of Management Accountants, 2017; Mio, et al., 2016; Oyewo, et al., 2015; Trébucq \& Magnaghi, 2017; Wulf et al., 2014). This role can, and must, be appreciated not only in light of the contribution that management control systems can offer merely because it is more closely linked to its 'institutional' ends, namely those relating to the production of information and the calculation of indicators. Rather, it should be understood by extending the perspective of observation to include other dimensions, not necessarily technical ones, which are however of fundamental importance to ensure the effective implementation of an IR (De Villiers et al., 2017; Kerr et al., 2015).

The case of the AOU shows the multiple roles and functions ascribable to the management accountant and to the management control system with reference to the design and the implementation of an IR system. As the empirical evidence has shown, adopting an IR requires constant support from the management accountant who is called to go beyond the mere production of information or the calculation of indicators (Owen, 2013; Wulf et al., 2014). Rather, he must take care of aspects which are more strictly connected to the organisation of the design process, increase the level of involvement and motivation of the subjects involved in the project, and intervene 
with reference to the best IR configuration that can express and represent the way in which the company creates value. In essence, the management accountant is called to go beyond the functions normally pertaining to a so-called 'bean counter' and to embrace new dimensions in the goal of allowing the effective implementation of a complex tool with enormous information potential (Busco et al., 2014; Jinga \& Dumitru; Mio et al., 2016; Owen, 2013; Wulf et al., 2014). These are new challenges that can represent important critical issues for the management accountant and management control systems, but also constitute important moments of growth that both of them can benefit from. What has been said is particularly relevant in the context of healthcare organisations, like the AOU. In these realities, in fact, there is the need to be accountable for what has been done and to show how organisations can contribute to generate value. In line with this, the adoption of an IR and its effective preparation due to the presence of a competent management accountant can be fundamental since, by communicating what these organisations do and how they do it, their public image could improve and this, finally, can lead to the activation of a virtuous circle from which healthcare organisations can benefit.

The contributions of this paper can be fully appreciated from different aspects. First, and foremost, through the empirical analysis, the work answers the call for more studies on the role played by management accountants and management control systems with regard to the design and the implementation of an IR (De Villiers et al., 2017; Dumay et al., 2016; Perego et al., 2016). In addition to this, it has contributed to existing knowledge on integrated reporting by illustrating the case of an organisation which operates in the health sector. This has brought to light some criticisms which can arise when an IR is adopted in a context different from that of private companies, a topic which has been more often explored in the extant literature. Moreover, the paper also emphasises the different roles that management accountants are required to play when they are involved in the design and the implementation of an IR. In so doing, it contributes to the current knowledge on the role and the functions of management accountants by showing how the introduction of a new reporting tool, like the IR, can stimulate and foster new competencies and the development of new skills for these professional figures.

\section{Acknowledgements}

The authors want to thank Vania Carignani, the management accountant of the Azienda Ospedaliero Universitaria Ospedali Riuniti Ancona, and Prof. Stefano Marasca for the precious and useful suggestions provided during the preparation of this paper.

\section{References}

Abeysekera, I. (2013). A template for integrated reporting. Journal of Intellectual Capital, 14(2), 227-245. https://doi.org/10.1108/14691931311323869

Adams, C. A. (2014). The International Integrated Reporting Council: A call to action. Critical Perspectives on Accounting, 27, 23-28. https://doi.org/10.1016/j.cpa.2014.07.001

Adams, C.A. (2017). Conceptualising the contemporary corporate value creation process. Accounting, Auditing \& Accountability Journal, 30(4), 906-931. http://dx.doi.org/10.1108/AAAJ-04-2016-2529

Adams, S., \& Simnett, R. (2011). Integrated Reporting: An opportunity for Australia's not for profit sector. Australian Accounting Review, 21(3), 292-301. http://dx.doi.org/10.1111/j.1835-2561.2011.00143.x

Barth, M. E., Cahan, S. F., Chen L., \& Venter, E. R. (2017). The economic consequences associated with integrated report quality: Capital market and real effects. Accounting, Organizations and Society, 62, 43-64, https://doi.org/10.1016/j.aos.2017.08.005

Beck, C., Dumay, J., \& Frost, G. (2017). In pursuit of a 'single source of truth': from threatened legitimacy to Integrated Reporting. Journal of Business Ethics, 141(1), 191-205. https://doi.org/10.1007/s10551-014-2423-1

Brown, J., \& Dillard, J. (2014). Integrated reporting: On the need for broadening out and opening up. Accounting, Auditing \& Accountability Journal, 27(7), 1120-1156. http://dx.doi.org/10.1108/AAAJ-04-2013-1313

Buck, P.N., \& Johanson, U. (2003). Research and knowledge interaction: Guidelines for intellectual capital reporting. Journal of Intellectual Capital, 4(4), 576-587. https://doi.org/10.1108/14691930310504572

Burke, J.J., \& Clark, C.E. (2016). The business case for integrated reporting: Insights from leading practitioners, regulators, and academics. Business Horizons, 59(3), 273-283. https://doi.org/10.1016/j.bushor.2016.01.001

Busco, C., Frigo, M. L., Quattrone, P., \& Riccaboni, A. (2013). Integrated Reporting. Concepts and cases that Redefine Corporate Accountability. London: Springer.

Busco, C., Frigo, M. L., Quattrone, P., \& Riccaboni, A. (2014). Leading practices in Integrated Reporting. 
Strategic Finance, 96(9), 23-32

Chartered Institute of Management Accountants (CIMA). (2017). Integrated Thinking. Aligning purpose and the business model to market opportunities and sustainable performance. Retrieved from http://integratedreporting.org/wp-content/uploads/2017/12/Integrated-Thinking-Report-vol-13_3CIMA.pdf

Cheng, M., Green, W., Conradie, P., Konishi, N., \& Romi, A. (2014). The International Integrated Reporting framework: key issues and future research opportunities. Journal of International Financial Management \& Accounting, 25(1), 90-119. https://doi.org/10.1111/jifm.12015

Chiucchi, M.S. (2013). Measuring and reporting intellectual capital: lessons learnt from some interventionist research projects. Journal of Intellectual Capital, 14(3), 395-413. https://doi.org/10.1108/JIC-03-2013-0036

Chiucchi, M.S., Montemari, M., \& Gatti, M. (2018). The influence of Integrated Reporting on management control systems: A case study. International Journal of Business and Management, 13(7), 19-32. https://doi.org/10.5539/ijbm.v13n7p19

Clarkson, P.M., Overell, M.B., \& Chapple, L. (2011). Environmental reporting and its relation to corporate environmental performance. Abacus, 47(1), 27-60. https://doi.org/10.1111/j.1467-6281.2011.00330.x

De Villiers C., Rinaldi L., \& Unerman J. (2014). Integrated Reporting: insights, gaps and an agenda for future research. Accounting, Auditing and Accountability Journal, 27(7), 1042-1067. https://dx.doi.org/10.1108/AAAJ-06-2014-1736

De Villiers, C., Venter, E.R., \& Hsiao, P.K. (2017) Integrated Reporting: Background, measurement issues, approaches and an agenda for future research. Accounting \& Finance, 57(4), 937-959. http://dx.doi.org/10.1111/acfi.12246

Dumay, J. (2010). A critical reflective discourse of an interventionist research project. Qualitative Research in Accounting and Management, 7(1), 46-70. https://doi.org/10.1108/11766091011034271

Dumay, J., \& Dai T. (2017). Integrated thinking as a cultural control? Meditari Accountancy Research, 25(4), 574-604. https://doi.org/10.1108/MEDAR-07-2016-0067

Dumay, J., Bernardi, C., Guthrie, J., \& Demartini, P. (2016). Integrated reporting: A structured literature review. Accounting Forum, 40(3), 166-185. https://doi.org/10.1016/j.accfor.2016.06.001

Eccles, R.G., \& Krzus, M.P. (2010). One Report. Integrated Reporting for a Sustainable Strategy. Hoboken: John Wiley \& Sons.

Feng, T., Cummings, L., \& Tweedie, D. (2017). Exploring integrated thinking in integrated reporting - an exploratory study in Australia. Journal of Intellectual Capital, 18(2), 330-353. https://doi.org/10.1108/JIC-06-2016-0068

Flower, J. (2015). The International Integrated Reporting Council: A story of failure. Critical Perspective on Accounting, 27, 1-17. https://doi.org/10.1016/j.cpa.2014.07.002

Frías-Aceituno, J.V., Rodríguez-Ariza, L., \& García-Sánchez, I.M. (2013). Is integrated reporting determined by a country's legal system? An exploratory study. Journal of Cleaner Production, 44, 45-55, https://doi.org/10.1016/j.jclepro.2012.12.006

Girella, L. (2018). The boundaries in financial and non-financial reporting. A comparative analysis of their constitutive roles. New York: Routledge.

Girella, L, \& Zambon, S. (2013). A political economy of intangibles reporting: the case of Japan. Journal of Intellectual Capital, 14(3), 451-470. https://doi.org/10.1108/JIC-03-2013-0040

Giovannoni, E., \& Maraghini, M.P. (2013). The challenges of integrated performance measurement systems: Integrating mechanisms for integrated measures. Accounting, Auditing \& Accountability Journal, 26(6), 978-1008. https://doi.org/10.1108/AAAJ-04-2013-1312

Grey, R., Kouhy, R., \& Lavers, S. (1995). Corporate social and environmental reporting: a review of the literature and a longitudinal study of UK disclosure. Accounting, Auditing \& Accountability Journal, 8(2), 47-77. https://doi.org/10.1108/09513579510146996

Gray, R., Owen, D., \& Maunders, K. (1988). Corporate social reporting: emerging trends in accountability and the social contract. Accounting, Auditing \& Accountability Journal, 1(1), 6-20. https://doi.org/10.1108/EUM0000000004617

Gunarathne, N., \& Senaratne S. (2017). Diffusion of integrated reporting in an emerging South Asian (SAARC) 
nation. Managerial Auditing Journal, 32(4/5). https://doi.org/10.1108/MAJ-01-2016-1309

Guthrie, J., Manes Rossi F., \& Orelli R.L. (2017). Integrated reporting and integrated thinking in Italian public sector organisations. Meditari Accountancy Research, 25(4), 553-573. https://doi.org/10.1108/MEDAR-06-2017-0155

Guthrie, J., \& Parker, L.D. (1989). Corporate social reporting: a rebuttal of legitimacy theory. Accounting and Business Research, 19(76), 343-352. https://doi.org/10.1080/00014788.1989.9728863

Guthrie, J. \& Petty, R. (2000). Intellectual capital: Australian annual reporting practices. Journal of Intellectual Capital, 1(3), 241-251. https://doi.org/10.1108/14691930010350800

Haller, A., \& Van Staden, C. (2014). The value added statement-an appropriate instrument for Integrated Reporting. Accounting, Auditing \& Accountability Journal, 27(7), 1190-1216. http://dx.doi.org/10.1108/AAAJ-04-2013-1307

Higgins, C., Stubbs, W., \& Love, T. (2014). Walking the talk(s): Organisational narratives of integrated reporting. Accounting, Auditing \& Accountability Journal, 27(7), 1090-1119. https://doi.org/10.1108/AAAJ-04-2013-1303.

IIRC. (2013). International $\quad<\mathrm{IR}>\quad$ Framework. $\quad$ Retrieved from http://integratedreporting.org/resource/international-ir-framework

Institute of Management Accountants (IMA). (2016). Integrated Reporting. Statement on Management Accounting. Retrieved from https://www.imanet.org/insights-and-trends/external-reporting-and-disclosure-management/integrated-repor ting? ssopc $=1$

Jensen, J.C., \& Berg, N. (2012), Determinants of traditional sustainability reporting versus integrated reporting. An institutionalist approach. Business Strategy and the Environment, 21(5), 299-316. https://doi.org/10.1002/bse.740

Jinga, G., \& Dumitru, M. (2014). Management accounting tools: support for integrated reporting. Proceedings of the 2nd International Scientific Conference on IFRS: Global rules and local use, Prague, October.

Jönsson, S., \& Lukka, K., (2005). Doing interventionist research in management accounting. Göteborg: Gothenburg Research Institute.

Kasanen, E., Lukka, K., \& Siitonen, A. (1993) The constructive approach in management accounting research. Journal of Management Accounting Research, 5, 241-264.

Kerr, J., Rouse, P., \& De Villiers, C. (2015). Sustainability reporting integrated into management control systems. Pacific Accounting Review, 27(2), 189-207. http://dx.doi.org/10.1108/PAR-08-2012-0034

Lodhia, S. (2015). Exploring the Transition to Integrated Reporting through a practice lens: An Australian customer owned bank perspective. Journal of Business Ethics, 129(3), 585-598. https://doi.org/10.1007/s10551-014-2194-8

Loprevite S., Rupo D., \& Ricca B. (2018). Integrated Reporting practices in Europe and value relevance of accounting information under the framework of IIRC. International Journal of Business and Management, 13(5), 1-12. https://doi.org/10.5539/ijbm.v13n5p1

Lukka, K. (2000). The key issues of applying the constructive approach to field research. In Reponen T. (ed), Management expertise for the new millennium. In Commemoration of the 50th anniversary of the Turku School of Economics and Business Administration, Publications of the Turku School of Economics and Business Administration, 113-128.

Lukka, K. (2005). Approaches to case research in management accounting: the nature of empirical intervention and theory linkage. In Jönsson, S., \& Mouritsen J. (Eds.), Accounting in Scandinavia - The northern lights, (pp. 375-399). Malmö: Liber \& Copenhagen Business School Press.

Manes Rossi, F. (2018). Is integrated reporting a new challenge for public sector entities?. African Journal of Business Management, 12(7), 172-187. http://10.5897/AJBM2018.8498

Manes Rossi, F., Nicolò, G., \& Orelli R. L. (2017). Reshaping risk disclosure through Integrated Reporting: Evidence from Italian early adopters. International Journal of Business and Management, 12(10), 11-23. https://doi.org/10.5539/ijbm.v12n10p11

McNally, M., Cerbone, D., \& Maroun, W. (2017). Exploring the challenges of preparing an integrated report. 
Meditari Accountancy Research, 25(4), 481-504. https://doi.org/10.1108/MEDAR-10-2016-0085

Mio, C., Fasan, M., \& Pauluzzo, R. (2016). Internal application of IR principles: Generali's Internal Integrated Reporting. Journal of Cleaner Production, 139, 204-218. https://doi.org/10.1016/j.jclepro.2016.07.149

Niskala, M., \& Pretes, M. (1995). Environmental reporting in Finland: a note on the use of annual reports. Accounting, Organizations and Society, 20(6), 457-466. https://doi.org/10.1016/0361-3682(94)00032-Q

Oliver, J., Vesty, G., Brooks, A. (2016). Conceptualising integrated thinking in practice. Managerial Auditing Journal, 31(2), 228-248. https://doi.org/10.1108/MAJ-10-2015-1253

Owen, G. (2013). Integrated Reporting: A Review of developments and their Implications for the accounting curriculum. Accounting Education, 22(4), 340-356. http://dx.doi.org/10.1080/09639284.2013.817798

Oyewo, B., Obigbemi, I., \& Uwuigbe, U. (2015). Should Integrated Reporting be incorporated in the management accounting curriculum? International Journal of Education and Research, 3(1), 63-76.

Paolucci, G., \& Cerioni, E. (2017). Integrated Reporting and Italian companies: An empirical investigation. International Journal of Business and Management, 12(9), 221-230. https://doi.org/10.5539/ijbm.v12n9p221.

Perego, P., Kennedy, S., \& Whiteman, G. (2016). A lot of icing but little cake? Taking integrated reporting forward. Journal of Cleaner Production, 136, 53-64. https://doi.org/10.1016/j.jclepro.2016.01.106

Serafeim, G. (2015), Integrated Reporting and investor clientele. Journal of Applied Corporate Finance, 27, 34-51. https://doi.org/10.1111/jacf.12116

Steyn, M. (2014). Organisational benefits and implementation challenges of mandatory integrated Reporting: Perspectives of senior executives at South Africa listed companies. Accounting, Management and Policy Journal, 5(4), 476-503. http://dx.doi.org/10.1108/SAMPJ-11-2013-0052

Stubbs, W., \& Higgins, C. (2014). Integrated Reporting and internal mechanisms of change. Accounting, Auditing and Accountability Journal, 27(7), 1068-1089. https://doi.org/10.1108/AAAJ-03-2013-1279

Suomala, P., Lyly-Yrjänäinen, J., Laine, T., \& Mitchell, F. (2017). Interventionist management accounting research: Theory contributions with societal impact. New York: Routledge.

Thomson, I. (2015). But does sustainability need capitalism or an integrated report? A commentary on "The International Integrated Reporting Council: A story of failure. Critical Perspectives on Accounting, 27, 18-22. https://dx.doi.org/10.1016/j.cpa.2014.07.003 1045-2354

Trébucq, S., \& Magnaghi, E. (2017). Using the EFQM excellence model for integrated reporting: A qualitative exploration and evaluation. Research in International Business and Finance, 42(C), 522-531. https://doi.org/10.1016/j.ribaf.2017.04.008

Van Bommel, K. (2014). Towards a legitimate compromise? An exploration of Integrated Reporting in the Netherlands. Accounting, Auditing and Accountability Journal, 27(7), 1157-1189. https://doi:10.1108/AAAJ-04-2013-1309.

Velte, P., \& Stawinoga, M. (2016). Integrated reporting: The current state of empirical research, limitations and future research implications. Journal of Management Control, 28(3), 275-320. https://doi.org/10.1007/s00187-016-0235-4

Veltri, S., \& Silvestri, A. (2015). The Free State University integrated reporting: a critical consideration. Journal of Intellectual Capital, 16(2), 443-462. https://doi.org/10.1108/JIC-06-2014-0077

Wulf, I., Niemoller, J., \& Rentzsch, N. (2014). Development toward integrated reporting, and its impact on corporate governance: a two-dimensional approach to accounting with reference to the German two-tier system. Journal of Management Control, 25(2), 135-164. https://doi.org/10.1007/s00187-014-0200-z

Yongvanich, K., \& Guthrie, J. (2006). An extended performance reporting framework. Business Strategy and the Environment, 15, 309-321. https://doi.org/10.1002/bse.541

\section{Copyrights}

Copyright for this article is retained by the author(s), with first publication rights granted to the journal.

This is an open-access article distributed under the terms and conditions of the Creative Commons Attribution license (http://creativecommons.org/licenses/by/4.0/). 